\title{
HUBUNGAN POLA ASUH ORANG TUA TERHADAP KEJADIAN SIBLING RIVALRY PADA ANAK DI RW 002 KELURAHAN BUKIT TEMPAYAN KECAMATAN BATU AJI KOTA BATAM
}

\section{The Relationship Of Parenting Pattern With The Rivalry Sibling At RW 002 Kelurahan Bukit Tempayan Batu aji Kota Batam}

\section{Septi Maisyaroh Ulina Panggabean $^{\text {।* }}$}

*ISTIKes Awal Bros Batam,Batam, Kep.Riau, Indonesia

*email: septi.panggabean190989@gmail.com

\begin{abstract}
Abstrak
Cara orang tua mendidik dan membesarkan anak dipengaruhi oleh banyak faktor antara lain faktor budaya, agama, kebiasaan, kepercayaan, serta kepribadian orang tua. Penelitian ini ditujukan untuk mengetahui hubungan antara pola asuh orang tua dengan kejadian sibling rivalry pada anak.

Penelitian ini merupakan penelitian analitik korelasi dengan pendekatan cross sectional, sampel yang diambil total populasi dengan tekhnik accidental sampling, jumlah sampel sebesar 20 responden.

Hasil penelitian didapatkan sebagian besar anak mengalami kejadian sibling rivalry, dari hasil uji Chi-Square goodness of fit nilai $p$ value 0,001 dengan taraf signifikansi : 0,05 , artinya ada hubungan yang signifikan antara pola asuh orang tua dengan kejadian sibling rivalry.

Dari penelitian ini dapat diketahui bahwa sebagian besar responden yang menerapkan pola asuh otoriter dan pemanja terjadi sibling rivalry pada anak. Orang tua perlu mengetahui dan memahami dalam menerapkan pola asuh yang sesuai dengan tahap perilaku anak. Diperlukan penyuluhan dan buku panduan mengenai pola asuh yang sesuai dengan fase perkembangan anak.
\end{abstract}

\begin{abstract}
The way parents educate and raise children is influenced by many factors such as culture, religion, customs, beliefs, and personality of the parents. This study aimed to determine the relationship between parenting parents with the incidence of sibling rivalry in children.
\end{abstract}

This study is an analytical cross sectional correlation, the total population of samples taken with accidental sampling technique, the sample size of 20 respondents.

The results showed the majority of children experience sibling rivalry events, from the results of Chi-Square test of goodness of fit $p$ value of 0.00 I with a significance level of: 0.05 , meaning that there is a significant relationship between parenting parents with the incidence of sibling rivalry.

From this study it can be seen that most of the respondents who apply pemanja authoritarian parenting and sibling rivalry occurs in children. Parents need to know and understand in applying parenting according to the stage of the child's behavior. Necessary counseling and guidance on parenting books that fit the child's development phase.

\author{
Parent's Parenting Pattern, \\ Sibling Rivalry \\ Etc \\ Kata Kunci: \\ Sibling Rivalry \\ Dst
}

(C) year The Authors. Published by Institute for Research and Community Services Universitas Muhammadiyah Palangkaraya. This is Open Access article under the CC-BY-SA License (http://creativecommons.org/licenses/bysa/4.0/). DOI: https://doi.org//0.33084/jsm.vxix.xxx.

\section{PENDAHULUAN}

Dalam dunia keluarga, sering kali ada persaingan untuk "mendapatkan" kasih sayang orang tua. Sejak anak-anak pertama muncul, mereka mungkin berlanjut hingga dewasa. Perselisihan saudara terjadi karena anak-anak merasa bahwa orang tua yang merawat mereka, dan perhatian yang berlebihan kepada saudara dapat menimbulkan kecemburuan dan persaingan antar saudara. Anak-anak menggunakan metode yang berbeda untuk menarik perhatian orang tua mereka, tetapi metode yang digunakan seringkali tidak sesuai dengan persyaratan perilaku yang diharapkan dalam lingkungan 
sosial mereka. Persaingan antar saudara (sibling rivalry) merupakan kecemburuan dan kebencian yang biasa dialami anak ketika saudara mereka lahir / hadir. (Djamarah,20I4).

Persaingan saudara biasanya terjadi ketika perbedaan usia pada usia yang sama terlalu dekat. Perbedaan usia yang biasanya memicu persaingan saudara adalah kesenjangan usia antara I-3 tahun, yang muncul antara 3-5 tahun, kemudian muncul kembali pada usia 8 - 12 tahun (Setiawati\&Zulkaida,2007).

Anak-anak, sebagai individu yang unik, memiliki kebutuhan yang sesuai dengan tahapan perkembangannya. Anak-anak mempunyai kebutuhan yang berbeda-beda tergantung dari usia perkembangannya. Perkembangan anak dalam kehidupan banyak ditentukan perkembangan psikologis yang termasuk didalamnya adanya perasaan kasih sayang atau hubungan anak dan orang tua atau orang lain disekelilingnya karena memperbaiki perkembangan psiko sosial. Terpenuhinya kebutuhan ini akan meningkatkan ikatan kasih sayang yang erat (bonding) dan terciptanya basic trust atau rasa percaya yang kuat (Maghfiroh, 20l4).

Asuhan orang tua sangat penting dalam menghadapi masalah yang sangat meresahkan pada anak akibat ikatan komunitas dan ikatan emosional yang mereka identifikasikan dengan keluarga. Pola asuh dalam kehidupan anak tidak hanya mempengaruhi kehidupan setiap anak, tetapi juga hubungan antar saudara. Persaingan saudara adalah masalah yang sangat sensitif karena seorang anak tidak hanya membandingkan dirinya dengan saudara kandung lainnya tetapi juga mengevaluasi bagaimana orang tuanya dibandingkan dengan saudara kandung lainnya. Ini merupakan beban berat bagi anak tersebut. Persaingan saudara bisa menguntungkan, tetapi biasanya anak merasa dipermalukan oleh orang tua mereka yang lebih memilih anak lain. Banyak masalah yang muncul karena pola asuh yang tidak tepat, seperti lebih memperhatikan anak lain, yang akan menimbulkan reaksi terhadap rivalitas saudara.

Salah satu aspek penting dalam hubungan orang tua dan anak adalah gaya pengasuhan yang diterapkan oleh orang tua. Pola asuh Otoritatif gaya pengasuhan yang bersikap responsive, menghargai dan mengikut sertakan anak dalam mengambil keputusan. Dan orang tua yang menerapkan pola asuh otoritatif cenderung lebih percaya diri dan mampu bergaul dengan teman sebayanya. Pola asuh otoriter gaya pengasuhan yang menuntut anak mengikuti perintah- perintah orang tuanya. Memberi batasan- batasan tegas dan tidak memberi kesempatan anak untuk berpendapat. Orang tua yang menerapkan pola asuh ini menjadikan anak bersifat curiga, anak tidak merasa bahagia, dan canggung bila berhubungan dengan teman sebayanya. Pola asuh Pemanja gaya pengasuhan yang cenderung membiarkan anak mereka melakukan apa aja yang mereka inginkan (Hanum AL,20I5).

Anak perlu diasuh dan dibimbing karena mengalami proses pertumbuhan dan perkembangan. Pertumbuhan dan perkembangan itu merupakan suatu proses. Agar pertumbuhan dan perkembangan berjalan sebaikbaiknya anak perlu diasuh, dan dibimbing oleh orang dewasa, terutama dalam lingkungan kehidupan keluarga. Peran orang tua adalah menciptakan lingkungan yang mendukung perkembangan anak kearah yang positif (Septiari BB, 20I2).

Hal negatif pada reaksi sibling rivalry bila dibiarkan, akan terus berlanjut sampai anak dewasa dan mempengaruhi kepribadian anak tersebut. Sibling rivalry membentuk unsur kompetisi, kecemburuan, kemarahan dan kebencian dalam hubungan saudara kandung. Unsurunsur ini yang mempengaruhi profil tingkah laku anak dalam bereaksi.

Perlakuan dan pola asuh orang tua merupakan faktor eksternal yang mempengaruhi sibling rivalry sehingga orang tua perlu mengetahui pola asuh yang berhubungan dengan sibling rivalry. Sibling rivalry merupakan hal penting yang harus mendapatkan perhatian orang tua 
karena penanganan yang tidak tepat dapat menimbulkan masalah yang berkelanjutan karena biasanya kecenderungan sibling rivalry yang terjadi pada kelompok umur berikutnya lebih disebabkan karena ketidaktuntasan dalam menyelesaikan sibling rivalry pada masa-masa sebelumnya.

Penelitian Idayanti (2014) menunjukkan bahwa pola asuh orang tua berhubungan dengan sibling rivalry. Dari hasil penelitian tabulasi silang dapat diketahui bahwa pola asuh penelantar dan permissive cenderung membentuk sibling rivalry tinggi, pola asuh otoriter cenderung membentuk sibling rivalry sedang, dan pola asuh demokratis cenderung membentuk sibling rivalry rendah. Kesimpulan dalam penelitian ini adalah orang tua (ibu) dari anak prasekolah di RA Tarbiyatus Shibyan Desa Gayaman cenderung menerapkan pola asuh demokratis, sebagian besar mengalami sibling rivalry rendah dan terdapat hubungan yang bermakna antara pola asuh orang tua dengan sibling rivalry (nilai $\mathrm{p}=$ 0,002) [3].

Dari Beberapa penelitian terdahulu dan Hasil studi pendahuluan yang telah dilakukan oleh peneliti pada tanggal 30 juni 2020 di RT 006 Kelurahan Bukit Tempayan Kecamatan Batu Aji Kota Batam menunjukkan bahwa dari 7 responden diperoleh 5 responden $(71,4 \%)$ menerapkan pola asuh autoritatif dan 2 responden (28,5\%) menerapkan pola asuh otoriter. Dari orang tua yang menerapkan pola asuh autoritaif diperoleh 3 anak (42,8\%) mengalami kejadian sibling rivalry dan 2 anak (28,5\%) tidak mengalami sibling rivalry.

Mengingat penelitian mengenai kejadian sibling rivalry sangat terbatas, dan penulis belum menemukan data yang mendukung kejadian tersebut di Kepulauan Riau, maka penulis merasa tertarik untuk melakukan penelitian tentang hubungan pola asuh orang tua terhadap kejadian sibling rivalry pada anak di RW 002 Kelurahan Bukit Tempayan Kecamatan Batu Aji Kota Batam.

\section{METODOLOGI}

Penelitian ini adalah penelitian kuantitatif yang desain penelitiannya analitik yaitu penelitian yang di arahkan untuk menjelaskan suatu keadaan atau situasi dengan menggunakan pendekatan cross sectional. Dalam penelitian ini, peneliti bermaksud membedakan, membagi variabel independen dengan variabel dependen. Populasidalampenelitianiniadalahorang tua yang mempunyaianakdi RW 002 Kelurahan Bukit Tempayan Kecamatan Batu Aji Kota Batam. Dalam penelitian ini, peneliti menggunakan tekhnik pengambilan sampel accidental sampling.

Pengumpulan data primer dilakukan dengan cara menyusun pertanyaan terstruktur berupa kuisioner, kuisioner disebarkan untuk memperoleh hubungan pola asuh orang tua terhadap kejadian sibling rivalry pada anak di RW 002 Kelurahan Bukit Tempayan Kecamatan Batu Aji Kota Batam.

\section{HASIL DAN PEMBAHASAN}

Adapun data yang disajikan pada penelitian ini berupa data umum yang mencakup karakteristik responden berdasarkan pola asuh dan data khusus yang memuat komponen utama berupa variabel - variabel yang diteliti. Jumlah responden yang teliti adalah 20 orang yang diambil datanya dengan menggunakan kuesioner dan lembar ceklis mulai tanggal 19 Juli sampai dengan 20 Juli 2020.

Tabel I. Distribusi Frekuensi Pola Asuh Orang Tua di RW 002 Kelurahan Bukit Tempayan Kecamatan Batu Aji Kota Batam Pada Tahun 2020

\begin{tabular}{ccc}
\hline $\begin{array}{c}\text { Pola Asuh Orang } \\
\text { Tua }\end{array}$ & Frekuensi & Presentase (\%) \\
\hline Autoritatif & 10 & 50 \\
\hline Permisif & 8 & 40 \\
\hline Otoriter & 2 & 10 \\
\hline Penelantar & 0 & 100 \\
\hline Total & 20 & bahwa pola
\end{tabular}

asuh yang diterapkan orang tua berdasarkan jenis pola 
asuh diketahui dari 20 orang tua yang menerapkan pola asuh autoritatif sebanyak 10 orang (50\%), pola asuh Permisif sebanyak 8 orang (40\%), dan pola asuh Otoriter sebanyak 2 orang (10\%).

Tabel II. Distribusi Frekuensi Kejadian Sibling Rivalry Pada Anak di RW 002 Kelurahan Bukit Tempayan Kecamatan Batu Aji Kota Batam Tahun 2020

\begin{tabular}{lcc}
\hline $\begin{array}{l}\text { Kejadian Sibling } \\
\text { rivalry }\end{array}$ & Frekuensi & Presentase (\%) \\
\hline $\begin{array}{l}\text { Terjadi Sibling } \\
\text { rivarly }\end{array}$ & 12 & $60 \%$ \\
\hline $\begin{array}{l}\text { Tidak terjadi } \\
\text { Sibling rivarly }\end{array}$ & 8 & $40 \%$ \\
\hline \multicolumn{2}{c}{ Total } & 20 \\
\hline
\end{tabular}

Dari tabel II menunjukkan bahwa jumlah kejadian sibling rivalry berdasarkan pola asuh yang diterapkan oleh orang tua yaitu sebanyak 12 anak (60\%) dan yang tidak mengalami kejadian sibling rivalry sebanyak 8 anak (40\%).

Tabel III. Hubungan Pola Asuh Orang Tua Terhadap Kejadian Sibling Rivalry di RW 002 Kelurahan Bukit Tempayan Kecamatan Batu Aji Kota Batam Tahun 2020

\begin{tabular}{|c|c|c|c|c|c|c|}
\hline \multirow{2}{*}{$\begin{array}{l}\text { Pola } \\
\text { Asuh }\end{array}$} & \multicolumn{4}{|c|}{ Kejadian Sibling Rivalry } & \multirow[t]{2}{*}{ Total } & \multirow[t]{2}{*}{$\%$} \\
\hline & Terjadi & $\%$ & $\begin{array}{l}\text { Tidak } \\
\text { terjadi }\end{array}$ & $\%$ & & \\
\hline Autoriatif & 2 & 20 & 8 & 80 & 10 & 100 \\
\hline Permisif & 8 & 100 & 0 & 0 & 8 & 100 \\
\hline Otoriter & 2 & 100 & 0 & 0 & 2 & 100 \\
\hline Penelantar & 0 & 0 & 0 & 0 & 0 & 0 \\
\hline Total & 12 & 60 & 8 & 40 & 20 & 100 \\
\hline
\end{tabular}

Dari data tabel diatas menunjukkan bahwa dari hasil penelitian dari pola asuh yang diterapkan oleh orang tua, jumlah kejadian sibling rivalry sebanyak 12 kejadian (60\%), sedangkan yang tidak terjadi sibling rivalry sebanyak 8 kejadian (40\%).

Dari hasil perhitungan Chi-Square didapatkan nilai pvalue sebesar 0,00 I karena hasil $p$-value $<0,05$ berarti HO ditolak, maka dapat disimpulkan bahwa ada hubungan yang signifikan antara pola asuh orang tua terhadap kejadian sibling rivalry pada anak.

Pembahasan dalam penelitian ini akan difokuskan untuk menjawab permasalahan penelitian yaitu adakah hubungan pola asuh orang tua terhadap kejadian sibling rivalry pada anak. Berdasarkan hasil dari tabulasi data didapatkan sebagian besar responden 12 orang (50\%) menerapkan pola asuh autoratif yang artinya cara orang tua mendidik dan membesarkan anak yang lebih memprioritaskan kepentingan anak diatas kepentingan dirinya sendiri. Selebihnya menerapkan pola asuh Permisif berjumlah 8 orang (40\%) dan sebagian kecil menerapkan pola asuh Otoriter 2 orang (20\%). Bila dilihat dari jenis pola asuh yang diterapkan orang tua, setelah dianalisa, peneliti menemukan bahwa Menurut Bronstein dan Cowan (1988) dalam Idayanti (2014), orang tua adalah kunci yang mungkin mempengaruhi sibling rivalry, namun orang tua pula yang dapat memperkecil terjadinya sibling rivalry.

Orang tua yang toleran memberikan kebebasan kepada anaknya untuk melakukan apa yang mereka inginkan, dan sangat lemah dalam disiplin anak. Orang tua yang toleran kurang percaya diri dalam melaksanakan aturan yang ada, sedangkan anak memiliki kesempatan untuk bertindak bebas dan mewujudkan keinginannya, hampir tanpa tanggung jawab. Dalam pola asuh otoriter, orang tua dapat menimbulkan kecemasan, mudah putus asa, tidak mampu merencanakan sesuatu, dan menolak anak lain (Idayanti,20I4)

Dalam penelitian ini pola asuh yang banyak digunakan oleh orang tua terhadap anak muda adalah pola asuh toleran dimana orang tua sangat memanjakan anaknya, orang tua tidak tegas ketika anak nakal dan melakukan kesalahan serta menuruti apa yang diinginkan anak. Untuk orang tua yang menggunakan pola asuh otoriter atau demokratis, orang tua selalu memantau aktivitas anak dan dengan cermat memeriksa apakah anak tersebut melakukan kesalahan, sedangkan orang tua yang menggunakan pola asuh otoriter lebih cenderung menuntut agar anaknya melakukan apapun yang 
diinginkan orang tua. Penelitian ini sejalan dengan Hasil penelitian Nur Agustin (2013) terhadap 52 responden diperoleh pola asuh demokratis $(32,7 \%)$, otoriter (3,8\%), permisif $(46,2 \%)$, penelantar $(17,3 \%)$, terjadi sibling rivalry $(65,4 \%)$ dan tidak terjadi sibling rivalry (34,6\%). Pada uji Chi Square diperoleh X2 hitung 2,8I < $X 2$ tabel 7,8I 5 artinya ada hubungan pola asuh dominan orang tua dengan sibling rivalry anak usia pra sekolah.

Asumsi peneliti adalah munculnya sibling rivalry pada balita cenderung terjadi pada orang tua yang menerapkan pola asuh pemisif dan otoriter, sedangkan pada orang tua yang menerapkan pola asuh authoritative atau demokratis menjadikan anak mandiri dan kecil kemungkinan untuk muncul sibling rivalry pada balita. Sebagai orang tua sebaiknya tidak terlalu mengengkang anaknya atau sebaliknya memanjakan anak. Hal itu kurang baik karena dapat menyebabkan sibling rivalry pada anaknya. Sebaiknya dalam memberikan pola asuh terhadap anaknya orang tua hendaknya berlaku demokratis yang memprioritaskan kepentingan anak, akan tetapi tidak ragu-ragu mengendalikan mereka terhadap semua anaknya. Sehingga anak tidak ada yang merasa paling istimewa atau merasa tidak dipedulikan oleh orang tuanya, maka masalah sibling rivalry bisa dicegah. Hurlock (2005) menyatakan bahwa pola asuh demokratis ditandai dengan sikap menerima responsif, berorientasi pada kebutuhan anak yang disertai dengan tuntutan, kontrol dan pembatas, penerapan pola asuh demokratis dapat memberikan keleluasaan anakuntuk menyampaikan segala persoalan yang dialaminya tanpa ada perasaan takut, keleluasaan yang diberikan orang tua tidak bersifat mutlak akan tetapi adanya kontrol dan pembatasan berdasarkan norma-norma yang ada.

Berdasarkan hasil tabulasi data didapatkan hasil bahwa 12 anak (60\%) mengalami kejadian sibling rivalry. Kejadian sibling rivalry dapat dipengaruhi oleh jenis dari pola asuh yang diterapkan oleh orang tua, dimana dari hasil penelitian diperoleh sebagian besar responden menerapkan pola asuh orotiter. Dari orang tua yang menerapkan pola asuh Permisif mengalami kejadian sibling rivalrysebanyak 8 anak (100\%).

Faktor penyebab sibling rivalry yaitu karena orang tua yang salah dalam mendidik anaknya, seperti sikap membanding-bandingkan anak yang satu dengan yang lainnya, tidak mempersiapkan anak untuk kelahiran adiknya, pilih kasih, serta cenderung tidak peduli terhadap anaknya. Hal ini menunjukkan bahwa pola asuh permisif merupakan pemicu terjadinya sibling rivalry, karena anak dari pola asuh permisif merasa tidak siap dengan kehadiran adiknya serta merasa minder dengan sau- daranya. Sehingga anak akan menjadi lebih agresif, menjadi nakal, bertingkah seperti adiknya untuk mencari perhatian orang tuanya.

Menurut Mia Cronan I, beberapa usaha dapat dilakukan untuk mengantisipasi terjadinya sibling rivalry. Salah satunya adalah dengan membicarakan dengan anak sebelum bayi lahir tentang segala hal yang akan terjadi setelah ia mempunyai adik nanti. Pada penelitian, orang tua yang menerapkan pola asuh permisif cenderung tidak mempersiapkan anak pertama untuk kelahiran adik barunya, seperti tidak mengajak kakak saat memeriksakan kehamilannya, tidak melibatkan anak untuk merawat adik. Sehingga anak dari pola asuh permisif berusaha untuk menyisihkan adiknya, karena merasa tidak dianggap oleh orang tuanya dan menganggap adik sebagai saingannya (Suherni, dkk. 2009).

Berdasarkan pernyataan Baumrind2 bahwa orang tua tipe otoritatif bersikap res- ponsif, menghargai dan menghormati pe- mikiran, perasaan, serta mengikutsertakan anak dalam pengambilan keputusan. Dari hasil penelitian, orang tua yang menerapkan pola asuh otoritatif 9 responden dengan kejadian tidak sibling rivalry 9 anak (64,3\%).

Hasil penelitian menunjukkan kejadian sibling rivalry pada anak kemungkinan dipengaruhi oleh jenis pola asuh yang diterapkan oleh orang tua. Pernyataan ini dapat dibuktikan dengan sebagian besar orang tua yang menerapkan pola asuh otoriter anaknya mengalami 
kejadian sibling rivalry. Menurut Boyle (2007) Sibling Rivalry yaitu reaksi yang sering ditampakkan adalah anak lebih agresif, memukul atau melukai kakak maupun adiknya, membangkang kepada ibunya, rewel, sering marah yang meledak-ledak, sering menangis tanpa sebab, menjadi lebih kolokan atau lengket dengan ibunya.

Hubungan Antara Pola Asuh Orang Tua Dengan Kejadian Sibling Rivalry Pada Anak Dari distribusi frekuensi antara pola asuh orang tua dengan kejadian sibling rivalry pada anak dapat diketahui bahwa seluruh responden yang menerapkan pola asuh otoriter dan pemanja, kejadian sibling rvalry pada anaknya sesuai menurut lembar ceklist. Pola asuh otoriter kebanyakan diterapkanoleh orang tua yang berasal dari pola pengasuhan otoriter pula dimasakanak-kanaknya (intergeneration transmission), cenderung berfokus pada masa kini, mengendalikan anak lebih karena kepentingan orang tua, mereka menilai dan menuntut untuk standa rmutlak yang ditentukansepihakoleh orang tua, memutlakkan kepatuhan dan rasa hormat atau sopan-santun orang tua merasa tidak pernah berbua tsalah (Prasetyo, 20I3).

Orang tua yang menerapkan pola asuh pemanja, sebagian besar anaknya juga mengalami kejadian sibling rivalry. Hal ini dikarenakan cara didik orang tua yang terlalu memanjakan dan membiarkan tingkah laku anaknya, tidak memandang dampak yang baik atau buruk terhadap anak. Menurut Yusuf (2006), orang tua menaruh perhatian terhadap perilaku anak yang baik dan memberikan kasih sayang. Perilaku ini perlu dilakukan sebagai pengganti dari kebiasaan orang tua yang pada umumnya suka menaruh perhatian kepada anak pada saat anak berperilaku menyimpang, namun membiarkannya ketika melakukan yang baik.

Sedangkan pada orang tua yang menerapkan pola asuh autoratif, sebagian besar tidak mengalami kejadian sibling rivalry. Hal ini karena cara orang tua dalam mengasuh anak dengan cara memberi kebebasan terhadap anaknya tetapi tetap mengarahkan dan memberi informasi kepada anak. Menurut Prasetyo (20I3), orang tua mengarahkan perilaku anak sesuai dengan kebutuhan anak sehingga anak memiliki sikap pengetahuan dan keterampilan yang mendasarinya untuk mengarungi hidup dan kehidupan di masa yang akan datang dan memberikan penjelasan atau dampak perbuatan yang baik dan buruk. Umumnya pola pengasuhan ini diterapkan orang tua yang menerima kehadiran anak dengan sepenuh hati serta memiliki pandangan dan wawasan kehidupan di masa depan dengan jelas.

Dari hasil analisis data dengan uji Chi-Square didapatkan bahwa ada hubungan antara pola asuh orang tua terhadap kejadian sibling rivalry pada anak

Hasil ini sesuai dengan pendapat Harlock (2005), bahwakejadian sibling rivalrydipengaruhi oleh pola asuh yang diterapkan oleh orang tua terhadap anak dalam keluarga tersebut

Orang tua merupakan sumber pendidikan yang pertama dan terpenting, karena sejak timbulnya adab kemanusiaan sampai sekarang orang tua selalu berpengaruh besar terhadap perkembangan anak manusia, karena itu kreatifitas anak tidak terlepas dari pengasuhan orang tua atau pendidik atau dalam arti kata bahwa kreatifitas anak erat hubungannya dengan pola asuh yang diberikan oleh orang tua atau pendidik dan yang mempengaruhi pola asuh yang mempengaruhi pola asuh yang diberikan oleh orang tua atau pendidik adalah lingkungan internal dan eksternal (Dewantoro, 2005). Pola asuhcara orang tua adalah metode yang dipilih orang tua sebagai metode pendidikan anak yaitu autoratif, otoriter, pemanja/penyabar, dan penelantar. Sebagian akan bergantung pada cara mereka sendiri dibesarkan dan sebagian pada apa yang berdasarkan pengalaman pribadi atau pengalaman teman, diketahuinya akan menghasilkan hasil yang diinginkan untuk anaknya kelak (Hurlock, 2005).

Orang tua merupakan pendidik pertama dan utama bagi anak. Orang tua berfungsi sebagai "transmitter budaya atau mediator sosial budaya bagi anak" maka fungsi 
orang tua dalam pendidikan adalah menyangkut penanaman, pembimbingan nilai-nilai agama, budaya dan ketrampilan-ketrampilan tertentu yang bermanfaat bagi anak dan konsisten dalam mendidik orang tua harus memiliki sikap dan perlakuan yang sama dalam melarang atau membolehkan tingkah laku tertentu kepada anak. Suatu tingkah laku anak yang dilarang oleh orang tua pada sewaktu-waktu harus juga dilarang apabila dilarang pada waktu lain (Yusuf, 20I5).

\section{KESIMPULAN}

Berdasarkan hasil uji statistic, didapatkan hasil bahwa pola asuh Permisif yang dilakukan oleh orang tua dapat mempengaruhi kejadian sibling rivalry diantara anak. Hal ini dikarenakan cara didik orang tua yang terlalu memanjakan dan membiarkan tingkah laku anaknya, tidak memandang

\section{UCAPAN TERIMA KASIH}

Terimakasih peneliti ucapkan kepada STIKes Awal Bros Batam dalam $\mathrm{Hal}$ ini Prodi Kebidanan yang telah memfasilitasi penelitian ini, seluruh enumerator yang telah membantu pengambilan data penelitian, serta para tokoh masyarakat dalam hal ini ketua RW 002 bukit tempayan yang telah memberikan izin penelitian di wilayah kerja bapak sebagai lahan penelitian.

\section{REFERENSI}

I. Agustin N. Hubungan Pola Asuh Dominan Orang Tua Dengan Sibling Rivalry Pada Anak Usia Pra Sekolah. Ponorogo: Universitas Muhammadiyah Ponorogo, Fakultas IImu Kesehatan; 2013.

2. Boyle,W.A. 2007. Sibling rivalry and why everyone should care about this ageold problem, http://www.angelifire.com.

3. Djamarah, Syaiful Bahri .2014. Pola Asuh Orangtua dan Komunikasi Dalam Keluarga. Jakarta: Rineka Cipta.

4. Hanum AL. Faktor Dominan Pada Kejadian Sibling Rivalry Pada Anak Usia Prasekolah. The Sun. 2015 Juni;
5. Hurlock, E.B. (2005). Pengkajian Pediatrik. Jakarta: Erlangga.

6. Idayanti T. Hubungan Pola Asuh Orang Tua dengan Sibling Rivalry Pada Anak Usia Prasekolah (3-6 tahun). Mojokerto: STIKes Dian Husada Mojokerto; 2014.

7. Maghfiroh L. Hubungan Pola Asuh Orang Tua Dengan Kejadian Sibling Rivalry Pada Balita di Desa Jotomsanur Kecamatan Tikung Kabupaten Lamongan. SURYA. 2014 Maret; I(XVII).

8. Prasetyto, G. T. (2003). Pola Pengasuhan Ideal. Jakarta: PT. Elex Media Komputindo.

9. Septiari BB. Mencetak Balita Cerdas dan Pola Asuh Orang Tua Yogyakarta: Nuha Medika; 2012

10. Setiawati dan Zulkaida Anita. 2007. Sibling rivalry pada anak sulung yang diasuh oleh single father. Proseding Pesat

II. Suherni, dkk. 2009. Perawatan Masa Ni- fas. Yogyakarta. Fitramaya

12. Yusuf, Muri. 2015. Assesmen dan Evaluasi Pendidikan. Jakarta: Prenada Media Group. 